\title{
Trend analysis of higher education abroad policy under the guidance of data
}

\author{
Anh Thu VO and Wanbing Shi
}

School of Humanities and Law Northeastern University, Shenyang, China

Keywords: Data orientation, higher education, study abroad policy, trend analysis.

\begin{abstract}
The policy of studying abroad has boosted the training of talents studying abroad and promoted the development of our study abroad. This paper reviews the evolution of our country since the reform and opening up policy of studying abroad and foreign students phenomenon change, analyzes students total and structure characteristics of groups, found that younger age, popular, become the current international trend of returning tide, and then from the youth entrepreneurship, youth education, youth culture and other aspects of interpretation of foreign influence on young the development of the. The classification and characteristics of diversification development orientation of the further development of higher education in China must adhere to the school, which is a fundamental requirement of education; the need to promote the construction of modern university system, this is the requirements of internal management of colleges and universities need to strengthen security; evaluation of effects on funding, this is high school external assurance requirements but also to guide the high school; the regional expansion, this is the comprehensive construction of a well-off society needs education.
\end{abstract}

\section{Introduction}

The policy of studying abroad is one of the national policies, which provides policy guidance for the training of high-level talents and the implementation of the national talent strategy. The policy of studying abroad has a direct impact on the training of overseas talents, which has an important influence on the development of young people. The past studies focused on the evolution of the policy itself or the students themselves change, and on the impact of policies on foreign and international students and foreign students group characteristics influence on the youth development research. Therefore, on the basis of sorting out the important policy of studying abroad and the number of students in different stages since China's reform and opening up, this paper analyzes the trend of the current study abroad. This paper presents the number and structural characteristics of the overseas students under the guidance of the policy of studying abroad, and analyzes the influence of the overseas study experience on the youth entrepreneurship, youth education and youth culture.

From the longitudinal study of historical development, both from the international education exchange and cooperation in education opening angle, or from after the accession to the WTO education service trade perspective, overseas education has made some achievements. The cause may be in many ways, different scholars can expound and analyze them from different angles, but one thing is for sure, this is the change of institutional environment in transition transition and innovation system in China and its shape, is the fundamental cause of overseas education development one of the reasons. This paper will change the system from a new perspective, to explain the intrinsic motivation system and explore the promotion and influence of educational development, through the combing and analysis of relevant policies, research on overseas education path dependence of institutional change and system innovation etc..

Our country should introduce and formulate clear policies to support the students studying in China, especially in the long-term development plan of the country. The education industry should be regarded as an important part of the agenda. At the same time, because the university evaluation results is an important sign of the level of running a university, the university internationalization level is an important indicator for the evaluation of the international higher education, so our country's higher education evaluation index system should be in line with international standards, the level of 
internationalization into the evaluation index system, and the number of school students should also be one of the most important as an international index. If the index system of the future the number of Chinese students in the university evaluation, will greatly enhance the degree of attention of university education for overseas students and funding autonomy, so as to promote the construction of hardware and software in education students.

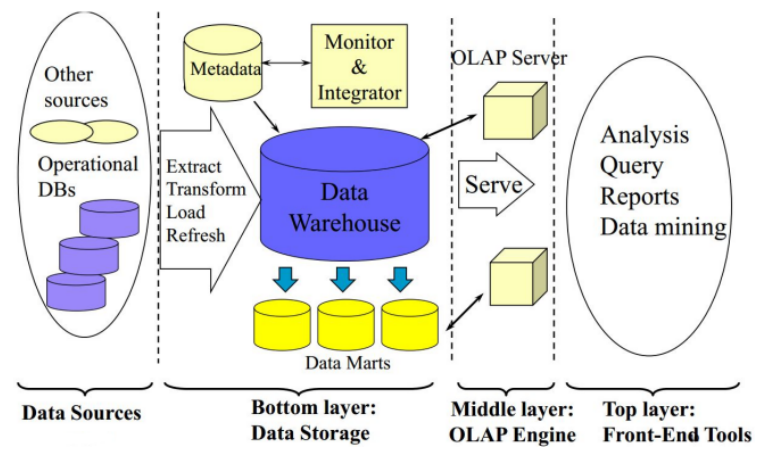

Figure 1. Data oriented

\section{The Proposed Methodology}

\subsection{Evolution of Studying Abroad Policy.}

Studying abroad means that a person receives all kinds of education from countries or regions other than his home country, and his study time is divided into short and long term. Studying abroad in broad sense includes overseas experiences aimed at enhancing knowledge or inspiring ideas. The policy of studying abroad refers to the relevant policies promulgated by the state, such as the basic guidelines for study abroad, the annual plan, the regulations and procedures for selecting personnel, the type of dispatch and the measures for administration.

Since the reform and opening to the outside world, our study abroad work has been gradually restored. In June 23, 1978, Deng Xiaoping made a speech at Tsinghua University to expand the number of students sent abroad. The following year, China and the United States reached an agreement to exchange students.

In terms of the dynamics of the number of foreign students, the number of students in China has been relatively small in the past 1952-1975 years. From the existing data, the average annual rate is about 300. In the past 1978-1981 years, the number of students in China has increased rapidly, reaching 860 people in 1978, with an increase rate of 251\%. This is closely related to the state leaders' attention and a number of overseas study policies promulgated in that year. In 1979, the number of students studying abroad exceeded 1000 for the first time, reaching 1777 people, but the growth rate dropped rapidly to $107 \%$. The rate of return for overseas students was $29 \%$ in 1978 , followed by a rapid decline to 8\% in the next two years, with a rapid rebound of 39\% in 1981.

\subsection{Policy Analysis of Higher Education.}

From the development stage, the development of higher education in China includes four periods: the first period, 1950 - 1977, that is, before the founding of new China to implement the policy of reform and opening to the outside world. This time our country to recruit students of one of the main characteristics of the policy is based on the diplomatic strategy need to develop recruitment policy, mainly for the friendly countries to establish diplomatic relations in our country to cultivate talent, and all foreign students can enjoy the scholarship provided by the Chinese government. The number of higher education for international students is very limited, mainly for the national diplomatic strategic services, and ideology is the key factor affecting the admission and training of foreign students.

Second periods, 1978 - 1989. During this period the world political situation has undergone tremendous changes, the two camps confrontation pattern is gradually replaced by the pattern of the world. After the party's the third Plenary Session of the 11th CPC Central Committee, China put forward economic construction as the center, and carried out the reform and opening up. During this 
period, the number of students receiving self financed students increased rapidly, and the total number of students has reached 26522.

Third periods, 1990 - 2000. During this period, due to China's further deepening of reform and opening wider to the outside world, China made a positive adjustment in the recruitment policy, and ushered in an unprecedented period of development in China's overseas education. Between 1990 and 1999, China received a total of 284424 students from abroad, about 4 times in the forty years from 1950 to 1989. The total number of students admitted to China was ten times. The institutions of higher learning that have received students from abroad have expanded from 192 in 1990 to 346 in 2000.

The fourth period, since 2001. After entering the new century, in promoting the integration of global economy and the internationalization of education, the education of overseas students in the field of international services trade and overseas in the form of consumption by the "general agreement on trade in services" (GATS) a new stage of development in the specification. Overseas consumption in the international education service trade in the largest market share, especially overseas consumption for higher education has become the world's most industrialized nature and open the highest level of international education service trade form. In the leadership of the government and the strong support of overseas students, the scale of higher education expands unceasingly, the annual growth rate of fifteen during the period of overseas students in China are about $20 \%$ foreign students at their own expense in 2007 has accounted for about $95 \%$ of the total number of the overseas students in china. China has received a total of foreign students 1 million 230 thousand people, an all-round, multi-level education opening pattern has been formed, which laid a good foundation for further promotion of the reform and development of education.

\subsection{Flow Trends of International Students.}

The proportion of international students in higher education is an important indicator of the degree of internationalization and international competitiveness of higher education in a country. The international student consists of international students accounted for the total number of students, the proportion of international students in the professional distribution, distribution of international students and the country (region) the number of students go abroad to study and exchange.

The 2008 annual UNESCO statistics report shows that with the development of international communication, the total number of international students at the end of 2007 in the world of learning has reached 2 million 720 thousand people by the end of 2008, the number has more than 3 million people. According to the 2007 foreign student exchange report of the Japanese Ministry of foreign affairs, according to estimates, by 2025, the total market for international students will reach 7 million, while the major ones will be concentrated in Asia. With the development of globalization and the increase of the demand for higher education, the total amount of international students' flow will gradually increase. Because the short-term financial crisis will not change the demand for higher education, the international student market will only grow bigger and will not shrink.

The distribution of international students into a country, which refers to the proportion of international students received by a country / region. If the world is divided into 8 regions: North America and Western Europe, East Asia and the Pacific, central and Eastern Europe, Arabia and sub Saharan Africa, Central Asia, Latin America, the Caribbean, South Asia, so students in North America and Western Europe accounted for the total number of students received the most. In 2005, the region received 1 million 850 thousand students, accounting for $67.8 \%$ of the total number of students. Followed by East Asia and the Pacific, which received $16.6 \%$ of the total students received.

The United States, Britain, Germany, France and Australia are the five largest recipients of foreign students. They receive $59.1 \%$ of the total number of international students. Since the reform and opening up, the number of Chinese students has increased rapidly, but compared with the big countries in Europe, America and East Asia and the Pacific, there is a big gap between them. In 2006, China received 36386 students from the mainland, accounting for only $1 \%$ of the total number of students.

\subsection{Inspiration and Countermeasures.}

Generally speaking, according to foreign students accounted for the total number of students in higher education institutions (the proportion of international students into rate) can be a country (area) 
the internationalization of higher education is divided into low (1\% 3\%), intermediate (3\% 5\%) and mature (5\% 8\%) three stages. At present, the proportion of China is only $0.8 \%$, while the United States, Britain, Germany and France have reached $6.6 \%, 18.1 \%, 11.6 \%$ and $7.6 \%$ in the early 2000 2001 years. There is a big gap between our country and the international students in these countries. As one of the world's most dynamic and most students sent abroad, the number of overseas students in China has increased significantly in recent years, the growth rate for 5 consecutive years of more than $10 \%$, showing a good momentum of development, but the overall scale of education in our country is still at a low level. As the most populous country in the world, China education scale and the number of students in some small European countries can not be compared, but the number of institutions of higher education and receiving students from the number of students in the proportion of China was only $0.83 \%$. Thus, as the largest developing country, compared with the number of foreign students and the higher education ability, there is still a big gap between the number of students studying abroad and the international average.

\subsection{Improving the Quality of International Students Education.}

In 2007 the Ministry of Education Service Center for overseas students in China National Statistics report shows that the annual foreign students studying in the long term education students accounted for only $34.89 \%$ of the total, the master's doctoral ratio is $11.18 \%$, the proportion was only $4.72 \%$. The student statistics annual report of 2007 Japanese Ministry of education shows that the annual students in undergraduate students in 61152, accounting for $50.2 \%$ of the total; graduate students 30278 people, accounting for $24.9 \%$ of the total; non degree students 1563 people, only $1.3 \%$ of the total. Compared with this, the educational level of foreign students in China should be improved urgently. Therefore, it is necessary to improve our higher education competitive advantage, offering high quality curriculum with distinctive Chinese characteristics, strengthen the international students education management and construction of teachers effective means, in order to further promote the education of overseas students in China towards high quality, high level of development.

\section{Conclusion}

In the era of global competition, the competition of national comprehensive strength is manifested as the competition of talent resources to a large extent, while the policy of studying abroad has a great influence on the realization of the strategy of "talent powerful nation" in china. At present, the new trend of young students, such as younger and more popular, is constantly emerging, and the influence of overseas study on young people's entrepreneurship, youth education and youth culture is strengthening day by day. In this context, how to keep the age of our country's study abroad policy, starting from the national strategy, making a timely judgment of the new situation, adjusting and formulating the corresponding policy of studying abroad is a new topic of the times. As a kind of education policy the policy of studying abroad for a long time, China is the talent policy, studying abroad is becoming more and more popular, the experience of studying or actual performance as the personnel evaluation standards, the problem of how to evaluate correctly the overseas experience, still need to be further in-depth discussed.

\section{Acknowledgments}

Fund Project: National Fund Pedagogy Project of Social Sciences "The Evaluation System Research of Universities Scientific Research Performance of Humanistic and Social Science” (Project No.: BFA150043)

\section{References}

[1]. Kuteeva, Maria, and John Airey. "Disciplinary differences in the use of English in higher education: Reflections on recent language policy developments." Higher Education 67.5 (2014): 533-549. 
[2]. Harmon, Grant. "Australia as an higher education exporter." International Higher Education 42 (2015).

[3]. Lam, Jason MS, David Yoon Kin Tong, and Ahmad Azmi M. Ariffin. "Exploring Perceived Risk and Risk Reduction Strategies in the Pursuit of Higher Education Abroad: A Case of International Students in Malaysia." Journal of Studies in International Education 21.2 (2017): 83-104. 